\title{
PerCursos
}

\section{Colapso do capital e a pandemia como desastre ambiental ${ }^{1}$}

\begin{abstract}
Resumo
O texto versa sobre a particularidade específica deste momento de colapso do capital. No centro, a pandemia provocada pelo vírus SARS-CoV-2, causador da doença COVID-19, a qual deve ser qualificada, entre outras formas, como desastre ambiental. Nosso argumento considera que a pandemia em si não deve ser tematizada como causa das mazelas atuais, mas sim como consequência do desenvolvimento nessa forma social do capital. Tratamos neste ensaio de como a pandemia não é o que pode gerar o colapso (já em curso), mas deve ser lida como expressão de um sistema que colapsa contínua e profundamente desde os anos de 1970, quando passou a demonstrar abertamente a sua incapacidade de extrair valor. Essa leitura pressupõe compreensão distinta sobre o seu enfrentamento, na contramão de posturas mistificadoras e negacionistas que vimos vivenciando no Brasil por parte do governo federal e da sociedade. A reflexão organiza-se em dois momentos: o primeiro, que qualifica o que entendemos por colapso dessa forma social e as suas particularidades relativas à nossa formação social; o segundo, que trata da epidemia como desastre ambiental e problematiza o universalismo de seu impacto.
\end{abstract}

Palavras-chave: Desenvolvimento econômico - Aspectos ambientais. Doenças transmissíveis - Epidemiologia. Covid-19.

\section{Luana Fernandes dos Santos Azeredo}

Assistente Social e Mestre em Serviço Social e Desenvolvimento

Regional pela Universidade

Federal Fluminense - UFF.

Doutoranda em Serviço Social na Universidade do Estado do Rio de Janeiro - UERJ.

Brasil

luana.fernandes.rr@gmail.com

\section{Tatiana Dahmer Pereira}

Assistente Social e Doutora em Planejamento Urbano e Regional pela Universidade Federal do Rio UFRJ. Professora da Universidade

Federal Fluminense - UFF. Pesquisadora apoiada pelo CNPq. Brasil

tatianadahmerpereira@gmail.com

\section{Para citar este artigo: \\ AZEREDO, Luana Fernandes dos Santos; PEREIRA, Tatiana Dahmer. Colapso do capital e a pandemia como desastre ambiental. PerCursos, Florianópolis, v. 21, n.46, p. 136 -161, maio/ago. 2020.}

\section{DOI: $10.5965 / 1984724621462020136$}

http://dx.doi.org/10.5965/1984724621462020136

\footnotetext{
${ }^{1}$ O presente trabalho foi realizado com apoio da Coordenação de Aperfeiçoamen $t$ to de Pessoal de Nível Superior - Brasil (CAPES) - Código de Financiamento 001.
} 


\title{
Capital collapse and the pandemic as environmental disaster
}

\begin{abstract}
The text deals with the specificity of this moment of capital collapse. In the center, the pandemic caused by the SARS-CoV-2 virus, which causes the disease COVID19, which must be qualified, among other ways, as an environmental disaster. Our argument considers that the pandemic itself should not be addressed as a cause of current problems but because of the development in this social form of capital. In this essay, we deal with how the pandemic is not what can cause the collapse (already underway), but should be read as an expression of a continuously and deeply collapsed system since the 1970 s when it starts to demonstrate its inability to extract value openly. This reading presupposes a different understanding of their confrontation, in the opposite direction of mystifying and denialist attitudes that we have experienced in Brazil by the federal government and part of society. The reflection is organized in two moments: the first qualifying what we mean by the collapse of this social form and its particularities regarding our social formation; the second dealing with the epidemic as an environmental disaster and questions the universalism of its impact.
\end{abstract}

Keywords: Economic development - Environmental aspects. Communicable diseases - Epidemiology. Covid19. 


\section{Introdução}

O artigo em questão, escrito em tempos de angústia e incertezas profundas, foca em leitura sociológica e histórica sobre o colapso do capital e o momento da pandemia do vírus SARS-CoV-2 - causador da doença Coronavírus (COVID-19) - e sua conformação processual como desastre ambiental. Não se trata de uma abordagem epidemiológica, nem do campo da saúde, mas de uma reflexão que se alicerça sobre a seguinte premissa: essa pandemia é bastante paradigmática de nossos tempos e do modo destrutivo e impessoal de dominação adotado pela forma do capital na modernidade. O que reverbera de seus impactos expressa muito das formas como construímos nossa sociabilidade e os tempos presentes.

No momento em que escrevemos este artigo, a pandemia de alcance planetário atingiu o patamar de 25.118.689 de pessoas com COVID-19 e 844.312 mortes no mundo (OMS, 2020)2. A despeito da dimensão mundial da propagação, sabemos que suas consequências não impactam igualmente os seres humanos, dada a combinação de dois elementos: (i) a conformação histórica dessa sociabilidade na sua formação como sistema mundo (WALLERSTEIN, 2001); (ii) e as características particulares da formação social de cada lugar, nas suas desigualdades internas e nas dinâmicas particulares de integração ao permanente, nefasto e claudicante movimento de acumulação mundial.

A reflexão presente foca sobre a particularidade da pandemia no contexto de colapso do capital: os elos fundamentais com suas causas e alguns desdobramentos em relação a essa situação no curso do desenvolvimento capitalista. Divide-se, assim, em dois momentos.

Primeiramente, construímos as bases de argumentação sobre a dimensão socialmente construída do colapso em curso como pressuposto para desmistificar o que consideramos abordagens naturalizadoras (e mistificadoras) sobre a epidemia.

Em seguida, refletimos sobre a questão da pandemia em si, ainda que possa ser precoce tratarmos de suas especificidades - mas, o foco é, justamente, qualificar como

\footnotetext{
2 Os dados da Folha Informativa OMS (OPAS) atualizados até 31 de agosto de 2020. Disponível em https://www.paho.org/pt/covid19. Acesso em 01/09/2020.
} 
essa condição deve ser reconhecida como desastre ambiental ao relacionar-se com a globalização contemporânea impulsionada pela dinamização mercantil extrema. Indicamos aí, de forma ainda incipiente, os distintos impactos dessa pandemia para sujeitos em desiguais condições em diferentes países e regiões (especialmente pensando a relação contraditória entre centro-periferia) e com base nas diversidades social, racial e sexual de existência das pessoas.

A base dessa construção estrutura-se em estudos pregressos em torno dos desastres ambientais como constitutivos dessa forma social e das mazelas produzidas pela (ir)racionalidade do desenvolvimento. Apesar de nos encontramos no "olho do furacão" e com crescente, mas ainda insuficiente, conhecimento sobre o vírus causador do adoecimento, seus impactos, e mesmo formas de enfrentamento fármaco e de políticas públicas, ensaiamos algumas ponderações sobre a questão a partir de uma lógica para além do trato epidemiológico e quantitativista em torno do monitoramento da doença e dos destroços que produz.

Os desdobramentos quanto aos impactos da doença, ainda que em curso e imprevisíveis, podem ser ponderados qualitativamente - não apenas pela novidade do vírus, mas pelo momento no qual este se expande no mundo: em um contexto de profunda crise da acumulação, no rumo adotado pelos Estados e instituições financeiras multilaterais de medidas neoliberais de ajustes econômicos, desproteção social e fragilização das relações de trabalho.

Desenvolvimento e o colapso do capital: o desastre ambiental como sua expressão

A formação da modernidade e, particularmente, das desigualdades sociais presentes, possui sua origem nas dinâmicas distintas do colonialismo nos diversos continentes. Após o lento e difuso cessar do denominado "pacto colonial” no século XIX, as ex-colônias nas Américas assumem papéis e posições distintos em relação aos países centrais, visto que agora essas economias periféricas tornaram-se nações 
“independentes” (MACHADO, 1999), porém marcadas por fortes pressões de integração subordinada à dinâmica de acumulação capitalista em sua era monopólica.

Segundo Nayyar (2014) a ascensão do “Ocidente" representou o declínio do “resto" na economia mundial. A dinâmica predatória de exploração dividiu o mundo entre os países que se industrializaram e exportavam manufaturas e os países que não conseguiram se industrializar e viviam da exportação de produtos primários. A partir disso, a formação do mundo moderno ocidental foi marcada por contradições indissociáveis, dentre as quais Mészáros (2011, p.73) sinaliza a impossibilidade de se “separar 'avanço' de destruição, nem 'progresso' de desperdício - ainda que as resultantes sejam catastróficas".

É no lastro da ideia de catástrofe que fundamentamos o que entendemos como elos estruturais da crise na qual nos encontramos. Qualificar crise é um desafio presente na literatura sociológica crítica $^{3}$. Na atualidade, mesmo com distintas leituras sobre a realidade e o processo histórico, parece existir alguma convergência quanto aos limites reais de recuperação do capitalismo a partir dos anos de 1970, configurando o que Mészáros (2011) nomeia como uma crise estrutural e o que Kurz (2017), com outra leitura, expõe como crise terminal. Como consequência, vivenciamos o colapso produzido permanentemente também como desastre ambiental e seus impactos devastadores na vida cotidiana.

Inicialmente, é importante sinalizar que o conceito de crise é central para a compreensão do tempo presente e dialogamos aqui com leituras que a sinalizam não como algo pontual, mas intrínseco à dinâmica da valorização e como expressão das próprias contradições inerentes à trajetória histórica do capital - especialmente relacionada ao seu desenvolvimento como algo predatório e que, dados os avanços tecnológicos e a crescente submissão do trabalho vivo ao trabalho morto, expõe o capital ao seu limite lógico (KURZ, 2017).

\footnotetext{
3 A qualificação desse conceito e sua compreensão como algo intrínseco à origem e dinâmica de acumulação (e não apenas como sua consequência episódica ou disfunção pontual) é algo que diferencia compreensões. Ainda dentro de leituras que qualificam historicamente a ruptura de um padrão de acumulação, a partir dos anos de 1970, há compreensões bastante distintas entre si, como as de Mészáros (2011), Kurz (2017) e Harvey (2013), as quais configuram debate interessante sobre a complexa substância desse conceito.
} 
Pelos próprios limites da acumulação e pela proposital inoperância do Estado em acabar ou mitigar os efeitos da crise, as consequências passam a ser cada vez mais destrutivas, sendo os desastres ambientais parte delas.

A particularidade dessa forma social é a objetificação de tudo e de todos, a mediação pelas relações mercantis e, necessariamente, a naturalização da construção social de algo (o Estado) que nos aparece como um ente mediador, mas materializa aquilo que Mascaro (2013) nomeia como "a condensação do domínio político em uma figura distinta da do burguês" seja esta "especificamente os contornos do fenômeno estatal” (MASCARO, 2013, p. 17). Porém, o Estado - como um complexo de relações sociais - não é “um aparato apenas instrumental” (MASCARO, 2013, p. 63), institucional, mas é constituído, condensa e expressa construções contraditórias em movimento das relações sociais. No caso de um país periférico e de fortes marcas escravistas e colonialistas como o Brasil, há particularidades históricas e territoriais relacionadas à complexidade dessa formação social.

Esse preâmbulo em torno do que compreendemos como capital como relação social, crise, Estado moderno e suas especificidades periféricas é fundamental para substanciarmos a noção de desastre, sua relação orgânica com essa forma social e a compreensão da crise como seu permanente colapso. Nosso entendimento sobre o que são os desastres ambientais considera que o acento expressivo dos mesmos se deve à dinâmica societária capitalista e é necessário entender as suas marcas específicas a partir de breve resgate sobre a formação social brasileira.

O acirramento do desenvolvimento capitalista - compreendido como expansão e intensificação da sua lógica de produção e de controle sobre a sociedade (BONENTE, 2016) - torna tardia e aceleradamente esse país agrário-exportador em uma nação industrializada. Esse processo social dominado pela forma capital, pelos seus fins de “valorização do valor” (MENEGAT, 2019) nos expõe

o fato de que, quando a indústria se tornou o eixo central da acumulação de capital no país, depois dos anos 1930, este modo de produzir já se 
acomodou entre nós nos seus estágios de desenvolvimento técnico mais avançado daquele tempo. (MENEGAT, 2019, p. 333)

Tal processo impõe um ritmo particular (e espoliador) de integração periférica à dinâmica capitalista monopolista internacional no início do século XX que, em interação com elementos da era colonial ${ }^{4}$ presentes na sociabilidade, fez o país trilhar um caminho de construção de profundas desigualdades sociais. Aliado a isso, a intensificada dinamização de relações mercantis, acirrada por crescente aglomeração do que viriam a ser os centros urbanos (Salvador/BA, Rio de Janeiro/RJ e São Paulo/SP, posteriormente) com frentes portuárias de escoamento de matérias-primas, abrigam espaços propícios à propagação de problemas de toda sorte: sociais, sanitários, entre outros. O Rio de Janeiro, em particular, se torna a "cidade febril" (CHALHOUB, 1996) em clara alusão à expansão descontrolada de epidemias como a varíola e a gripe na virada do século XIX para o XX, dadas as aglomerações e condições sanitárias insalubres.

A trajetória da formação social e territorial brasileira, portanto, se inscreve desde sua gênese com elementos constitutivos de processos de desastres ambientais, os quais têm se intensificado à medida que a sociabilidade capitalista se radicaliza.

Dados globais revelam que os desastres ambientais têm se intensificado, principalmente a partir da década de 1970, exatamente no contexto de expansão da crise estrutural do capital - momento a partir do qual se pode perceber o avanço predatório sobre pessoas trabalhadoras e empobrecidas e o ambiente que as cerca (CARMO; ANAZAWA, 2014).

Como o capitalismo moderno, justamente pelo desenvolvimento tecnológico e aniquilamento de postos de trabalho, chegou ao ponto de produzir uma massa populacional para além do exército industrial de reserva - configurando uma população sobrante tratada como vidas que podem se perder - vemos que esse sistema depende cada vez menos do trabalho vivo para girar a circulação de serviços e de mercadorias -

\footnotetext{
${ }^{4}$ Alguns exemplos desses elementos são: a massa populacional de pessoas que foram escravizadas e depois colocadas em liberdade sem nenhuma compensação ou restituição por essa condição pregressa; o modelo de exploração de matérias-primas altamente destrutivo; o monopólio da terra e a adoção de um relacionamento com os países dominantes pautado na submissão.
} 
porém, vivencia dilemas na extração do valor. Coloca-se aí o limite lógico do capital (KURZ, 1997), mencionado anteriormente, na medida em que é do trabalho vivo que se extrai valor. Isto é, com as revoluções tecnológicas, o trabalho vivo acaba crescentemente cada vez mais submetido (e subsumido) ao trabalho morto, contribuindo para a criação desse limite lógico para extração de valor e, consequentemente, para o aprofundamento da crise da dinâmica de acumulação.

Esse processo reverbera a desvalorização de vidas, sendo presente no cotidiano de diferentes formas: no extermínio pela polícia em relação às populações faveladas e periféricas (majoritariamente pretas) no Brasil; no encarceramento em massa em países como Estados Unidos, Brasil e China; em situações de grandes genocídios causados pelas guerras em diferentes cantos do mundo; ou nas milhares de mortes, fruto dos - frisa-se constantes desastres ambientais em diferentes partes do mundo.

Se o sistema capitalista se assenta sobre desigualdades para nascer - a despeito das promessas iluministas (ou talvez por causa delas) e revolucionárias burguesas - não causa espanto o ponto ao qual chegou, fomentando uma descartabilidade da vida.

Isso põe em foco a necessidade extrema em se problematizar o que são os desastres ambientais a partir de uma perspectiva desnaturalizadora, visto que ainda existe grande dificuldade no entendimento deles enquanto fenômenos sociais e historicamente construídos. Por muito tempo, manteve-se como paradigma a concepção desses fenômenos enquanto eventos naturais, imprevisíveis e desarticulados da estrutura societária5.

Apenas a partir da década de 1970 é que ganham peso produções científicas na área das ciências sociais, trazendo uma perspectiva de análise que considera aspectos da dinâmica societária na construção e intensificação dos desastres (GILBERT, 1995).

\footnotetext{
5 Conforme material da Universidade Federal de Santa Catarina (UFSC) para capacitação em proteção e defesa civil, esse enfoque representa o modelo de Hewitt (1997), "no qual os desastres são eventos extremos da natureza, imprevisíveis e inevitáveis, nos quais a sociedade tem papel dependente. Nesse modelo, a caracterização dos desastres privilegiava a tomada de medidas pós-desastre orientadas em restabelecer o panorama anterior ao evento destrutivo, diminuindo assim a responsabilidade dos encarregados da redução dos riscos de desastres" (UFSC, 2014, p. 76).
} 
Um dos ramos de investigação científica que tem representado essa vertente no Brasil é a "Sociologia dos Desastres", a qual "tem buscado se contrapor à interpretação predominante dos desastres, com base na afirmação de duas noções fundantes: desastres são considerados fenômenos sociais e têm origem na estrutura social" (DUTRA, 2018, p. 32). Em outras palavras, são

produtos de uma combinação particular entre ameaças e vulnerabilidades da sociedade; o que implica, na maioria dos casos, que são as condições sociais de existência de uma população que determinam fortemente o nível de destruição ou de interrupção de serviços essenciais numa sociedade. (UFSC, 2014, p. 76)

Nesse sentido, consideramos problemático o uso da expressão "desastres naturais", pois dificulta compreender esses contextos a partir de uma perspectiva crítica. Tal expressão por si só já traz uma conotação desses fenômenos como fruto de uma "lei natural" que rege a vida em sociedade, escondendo seus reais determinantes sociais. Partilhamos de Dutra (2018), ao afirmar que

\begin{abstract}
Naturais podem ser as chuvas, as secas, as erupções vulcânicas, porém, estas e outras manifestações da natureza somente se transformam em desastres quando se entrelaçam com determinadas condições de vida, de moradia, de saúde, em suma, de precariedade exacerbada pelas taxas de desigualdade encontradas na sociedade. Ainda que muitos destes processos venham à tona a partir da dimensão física, os mesmos são, essencialmente, de outra ordem. É no processo de tecitura cotidiana que vão se moldando os rostos das reais vítimas dos desastres, em sua imensa maioria pobres e não brancos, que assistem suas moradias precárias serem arrastadas pelas chuvas incessantes, que relembram seus parentes soterrados pela lama e pelos escombros, que constatam a contaminação de seus meios de sobrevivência por produtos tóxicos, enfim, que experimentam uma série de violações que vão muito além do momento do impacto. (DUTRA, 2018, p. 34-35)
\end{abstract}

Nossa análise considera que os desastres são ambientais como expressão de um ambiente social e historicamente produzido, e que se constituem, portanto, como processos. Assim, não compreendemos os desastres ambientais como fenômenos 
pontuais (o episódio do desastre em si), mas como processos que: (i) possuem um momento anterior à crise que se instala com o evento; (ii) a própria crise, considerada o momento mais agudo quando o risco se materializa; (iii) e a continuação desse processo com os efeitos/consequências que ainda perduram por um tempo.

Contribuindo para o debate, Beck (2010) traz em sua obra a análise sobre a falência das instituições políticas modernas, deteriorando-se, sobretudo, o campo da proteção social aos indivíduos, criando o que denomina por "sociedade do risco", cuja insegurança, a ineficiência, o autoritarismo e as desigualdades são marcas profundas.

Concordamos com o autor ao afirmar que o modelo de desenvolvimento econômico do sistema capitalista levou tanto à produção global de riquezas, como também à construção de riscos de diversas espécies. Assim, há a concentração e centralização das riquezas socialmente produzidas e, inversamente, a socialização desigual dos riscos decorrentes dessa dinâmica. Logo, são equivocadas e superficiais as análises que tratam os desastres ambientais como fatalidades, imprevisíveis e incontroláveis (UFSC, 2014), desvinculados dos processos antropogênicos que constroem e intensificam as desigualdades sociais.

Não afirmamos aqui que esses fenômenos são limitados aos tempos modernos (WALLERSTEIN, 2011), porém, a partir da instauração dessa nova sociabilidade, eles se intensificam, se tornam mais complexos e se expandem para todo o mundo principalmente a partir do processo de globalização, expressando-se como consequência de um modelo de desenvolvimento insustentável, excludente, predatório e genocida.

Cabe reforçar que em função da forma desigual que caracteriza essa sociabilidade, as pessoas diferentes (e distinguidas hierarquicamente a partir da centralidade das relações mercantis) submetem-se diferenciadamente a riscos e são impactadas de forma desigual quando estes se materializam. 


\section{A forma predatória do desenvolvimento e nexos com a pandemia}

Neste segundo momento, focamos em problematizar os elos do desenvolvimento nessa forma social e seus nexos com a pandemia de COVID-19 causada pelo vírus SARSCoV-2. Para tanto, iniciamos com algumas descrições existentes até o momento, guardadas as mediações e cautelas necessárias para se tratar de algo tão recente e ainda em fase de pesquisas.

Segundo a Organização Mundial da Saúde:

os coronavírus são uma grande família de vírus que podem causar doenças em animais ou humanos. Em humanos, sabe-se que vários coronavírus causam infecções respiratórias que variam do resfriado comum a doenças mais graves, como a Síndrome Respiratória do Oriente Médio (MERS) e a Síndrome Respiratória Aguda Grave (SARS). O coronavírus descoberto mais recentemente causa a doença de coronavírus COVID-19. (OMS, 2020a, sem paginação)

O COVID-19 é uma doença infecciosa causada pelo vírus SARS-CoV-2, registrada pela primeira vez em dezembro de 2019 na China (BRASIL, 2020a). O Painel Visual de monitoramento mundial da epidemia, alimentado pela Organização Mundial da Saúde (OMS), retrata que em 02 de setembro de 2020 há o quantitativo mundial de 25.602 .665 de pessoas infectadas e 852.758 mortes reportadas à Organização (OMS, 2020). Essa difusão infecciosa vem colapsando atendimentos na área da saúde em todo o mundo, explicitando os danos causados pelos constrangimentos de investimentos públicos no setor nessa era neoliberal, e a despeito de ser a sociedade capitalista a que mais produziu riquezas e tecnologia em toda a história.

Consideramos que a expansão da infecção já se configura como desastre ambiental em nível mundial. Para problematizar as contradições das políticas públicas regulatórias para tratar a pandemia como desastre ambiental, citamos a Instrução Normativa n. 1/2012 (BRASIL, 2012a), a qual estabelece os procedimentos e critérios para reconhecimento de situação de emergência ou estado de calamidade pública. Nela, os desastres são reconhecidos enquanto 
resultado de eventos adversos, naturais ou provocados pelo homem sobre um cenário vulnerável, causando grave perturbação ao funcionamento de uma comunidade ou sociedade envolvendo extensivas perdas e danos humanos, materiais, econômicos ou ambientais, que excede a sua capacidade de lidar com o problema usando meios próprios. (BRASIL, 2012a, p. 1)

Tal Instrução também classifica os desastres segundo sua origem, definindo-os como: Desastres naturais - "aqueles causados por processos ou fenômenos naturais [...].” (BRASIL, 2012a, p. 5); Desastres tecnológicos - "aqueles originados de condições tecnológicas ou industriais, incluindo acidentes, procedimentos perigosos, falhas na infraestrutura ou atividades humanas específicas [...].” (BRASIL, 2012a, p. 5).

Em consonância com essa Instrução Normativa, a Classificação e Codificação Brasileira de Desastres (COBRADE) (BRASIL, 2012b) os organiza em duas categorias já explicadas: desastres naturais e tecnológicos. Dentro da categoria dos desastres naturais, encontram-se cinco grupos dentre os quais, destacamos o grupo dos desastres naturais biológicos - estes compreendem as epidemias e infestações/pragas. A COVID-19, portanto, enquadra-se nessa classificação de desastre.

A partir desses documentos, três elementos principais merecem destaque considerando a questão das políticas regulatórias. O primeiro refere-se ao fato que tanto a Instrução Normativa quanto o COBRADE classificam de forma dicotômica os desastres entre naturais e tecnológicos, criando uma separação difícil de ser comprovada na dinâmica cotidiana.

Outro aspecto importante é que a Instrução Normativa reconhece que há desastres que podem ser provocados pelo ser humano. Porém, reforçamos que essas causalidades não podem, nem devem limitar-se ao campo da responsabilidade individual, mas situam-se dentro de condições objetivas em torno de uma sociabilidade sobre ser e estar no mundo. Ainda que existam responsabilidades que possam ser individualizadas em alguma medida, é importante perceber que a culpabilização em muito pouco ou nada enfrenta as reais causas dos problemas. 
Por fim, nossa argumentação não coaduna com essa definição de desastres, posto que se afirmam aí elementos relativos: (i) Ao trato do desastre como o episódio em si no momento agudo de sua ocorrência - e não como um processo estrutural socialmente construído; (ii) À exposição de determinadas populações ao risco, a partir da combinação de fatores, mas, é importante ressaltar que a vulnerabilidade não é um atributo particular a grupos sociais - mas produzidos pela constituição desigual da sociedade e a produção capitalista do espaço (HARVEY, 2013). Para que existam segmentos mais expostos ao risco em um momento histórico de significativo avanço científico, necessariamente significa que há a concentração do acesso aos recursos protetivos por parte de outros segmentos, provavelmente favorecidos socialmente; (iii) À ideia do risco como algo que pode ser bem ou mal gerido, como se estivesse limitado a uma questão de escolhas técnico-gerenciais neutras, padronizadas e passíveis de universalização.

Conforme já explicitado na seção anterior, consideramos os desastres ambientais como processos social e historicamente determinados, materializados através de fenômenos da natureza em interação com a estrutura da sociedade a ponto de materializar o risco, momento este que representa o ápice da crise do desastre.

Partindo desses pressupostos, podemos salientar uma chave de análise importante para o contexto em que o mundo se encontra, a saber, a mudança de uma visão da determinação natural para a determinação social da doença, cujos estudos já apontam elementos de análise desde o industrialismo (STARK, 1977).

A Revolução Industrial (1750, Inglaterra), por exemplo, precedida tanto pela acumulação primitiva sustentada pelo escravismo colonial, quanto pelo processo de cercamento dos campos, produziu uma dinâmica de migração e urbanização descontroladas, produzindo um problema habitacional (ENGELS, 2015). Foi na construção de cortiços e moradias precárias, portanto, que a população mais empobrecida encontrou alternativa de sobrevivência e de condições mínimas para a sua reprodução social, mesmo que significasse habitar em condições insalubres e sem infraestrutura sanitária, tornando esses locais de aglomeração focos para rápida disseminação de epidemias, já configurando a origem de constantes processos de desastres ambientais. 
A partir de uma análise superficial e higienista sobre o que nos aparece, se afirmava que a causa dessas epidemias seria a pobreza. Entretanto, a perspectiva crítica histórica investe em compreender determinações e realiza mediações em relação à realidade exposta, permitindo-nos identificar demais nexos causais e, propriamente, a base que o sustenta: o modo de produção capitalista a partir da instauração de uma nova dinâmica de produção, circulação e consumo de mercadorias; a apropriação privada dos meios de produção; as condições extremas de exploração do trabalho coletivo que passou a produzir grande riqueza, a qual é absorvida por uma pequena parcela da sociedade.

Se olharmos para a Inglaterra, onde o capitalismo surgiu primeiro no campo, através da limpeza em massa de camponeses da terra a ser substituída por monoculturas de gado, vemos os primeiros exemplos dessas pragas distintamente capitalistas. Três pandemias diferentes ocorreram na Inglaterra do século XVIII, abrangendo os períodos de 1709$1720,1742-1760$ e 1768-1786. A origem de cada uma foi gado importado da Europa, infectado pelas pandemias pré-capitalistas normais que se seguiram a guerras. Mas na Inglaterra o gado começou a se concentrar de novas maneiras, e a introdução do estoque infectado atingiria a população de maneira muito mais agressiva do que na Europa continental. Não é por acaso, então, que os surtos se concentraram nos grandes laticínios de Londres, que proporcionaram ambientes ideais para a intensificação do vírus. (COLETIVO CHUANG, 2020, sem paginação)

Assim, podemos compreender que a então nova forma de organização social passou a criar o cenário ideal para a proliferação de doenças em escala ampliada e mais agressiva, a despeito dos "avanços" científicos e capacidade de controle ambiental e sanitário. Isso posto, é possível afirmar que

nas sociedades capitalistas, onde a pobreza é construída para preservar a apropriação privada do excedente social do trabalho, as condições dos trabalhadores pobres, incluindo sua saúde, são um produto dinâmico de sua relação com a riqueza, não uma função da pobreza em si mesma. (STARK, 1977, p. 15) 
A doença não se trata, portanto, de um "intruso extraterritorial ou biológico, mas como um fato de dimensões socioeconômicas, ideológicas e políticas" (STARK, 1977, p. 4). No caso das epidemias, por exemplo, a contaminação se alastra por encontrar na base social condições ambientais, políticas, econômicas, sociais e ideológicas propícias para tanto.

Assim,

na medida em que se pode atribuir epidemias a causas sociais claramente definidas como pobreza, superpopulação ou distribuição desigual de serviços, elas podem ser pensadas como sendo - até certo ponto, propositadamente - feitas pelo, com e também para o povo. (STARK, 1977, p. 4)

Daí a importância de uma abordagem que permita a ligação dos fatores sociais e históricos relacionando o processo de doença com a dinâmica do desenvolvimento capitalista (STARK, 1977, p. 31).

A respeito dessas doenças, identificam-se ainda contradições entre discursos políticos e científicos. Como o enfrentamento requer a centralidade da mediação estatal justamente por possuir dimensão de saúde pública, implicando na tomada de decisões complexas e de alta alocação de recursos financeiros, identifica-se na contramão a emergência de discursos de cunho negacionista e naturalizador da realidade.

A pandemia que vivenciamos atualmente potencializa essas expressões. Enquanto o discurso de especialistas epidemiológicos caminha para a identificação e problematização da realidade, de conhecimento sobre a dinâmica dos medicamentos e estratégias de enfrentamento do vírus, e de eficiente quantificação desse quadro pandêmico, despontam líderes políticos voltados ao embate dessas práticas.

É importante reforçar que o acirramento de medidas neoliberais adotadas desde os anos de 1970 e a crescente situação de aprofundamento do colapso dessa forma social vêm produzindo um mundo marcado por contradições profundas e insolúveis. Têm sido, assim, crescentes as saídas extremistas que retomam princípios fascistas e se assentam sobre medidas xenófobas, racistas, higienistas e de controle sobre seres humanos, com base nas promessas de "segurança” e de retomada do chamado "desenvolvimento". 
A emergência de líderes eleitos como expressão de grande regressão política e de características fascistas em diferentes países, é expressão dessa saída pelo extremismo. A grande questão é que se coloca como embate à ciência - e obviamente, às leituras mais críticas - abordagens mistificadoras e que evocam o obscurantismo no trato de situações complexas, que tentam individualizar os problemas e dirimir o Estado de parte de sua responsabilidade no enfrentamento desse desastre.

Manifesta-se a disputa entre concepções ideológicas distintas acerca da origem dessa crise e que, consequentemente, levam também a caminhos contraditórios para sua resolução. Procura-se intensamente encontrar culpados, mas são encobertas questões fundamentais como: "por que chegamos a esse ponto?", "por que é tão difícil encontrar um protocolo comum entre as diferentes nações?", "por que as estruturas e serviços de saúde, em cada lugar, não conseguem atender a todas as demandas?", "por que os casos de contaminações por doenças provenientes do consumo de alimentos de origem animal têm aumentado?".

A respeito dos determinantes da pandemia que vivemos, os cientistas já há tempos avisam

que ao invadir os ecossistemas florestais, destruir os habitats de muitas espécies e manipular as plantas e os animais para obter lucro econômico, fomentamos o surgimento de novas doenças. Ao longo dos últimos 50 anos, apareceram 300 novos patógenos. Está escancaradamente documentado que $70 \%$ dos patógenos que afetam o ser humano, entre os quais estão o HIV, o ebola, a gripe, a síndrome respiratória do Oriente Médio (MERS, na sigla em inglês) e a síndrome respiratória aguda grave (SARS, na sigla em inglês) surgem quando os ecossistemas florestais são invadidos e os vírus se transferem de animais para pessoas. Quando se amontoam animais em fazendas industriais para maximizar os lucros, afloram novas doenças como a gripe suína e a aviária. (SHIVA, 2020, sem paginação)

Já se sabe que elementos como os "mercados úmidos" e o comércio de carne de caça contribuem para a ocorrência de epidemias (O CAMINHO..., 2020). Todavia, tão relevante quanto esses aspectos é a criação das chamadas "zonas quentes" a partir de atividades extrativistas, por exemplo. 


\begin{abstract}
À medida que os humanos penetram em áreas remotas da fronteira, eles liberam os patógenos que vivem com seus hospedeiros naturais. Tais patógenos podem ser devastadores quando saltam para os seres humanos[...]. Com nossos buldôzeres rugindo profundamente em ecossistemas remotos repletos de diversidade biológica e microbiana, estamos criando corredores de contágio - onde caçadores, mineiros, colonos e especuladores de terras podem facilmente pegar novos patógenos que, por sua vez, estimulam pandemias globais. ( $O$ CAMINHO..., 2020, sem paginação)
\end{abstract}

Além desses elementos que já somos capazes de evidenciar, faz-se importante também observarmos os desdobramentos dessa pandemia, visto que os desastres ambientais possuem grande capacidade de gerar um "efeito bola de neve". Em outras palavras, o desastre ambiental pode não se findar em si, mas constituir-se enquanto mais um elemento fomentador de outros fenômenos ${ }^{6}$.

Tudo isso evidencia como a incapacidade do ser humano em lidar com os limites da natureza e com os imperativos capitalistas tem levado a humanidade rumo ao abismo. A busca incessante pela competição, acumulação, maximização dos lucros, intensificação de fluxos mercantis e crescente produtividade do trabalho, tem esgotado não apenas as fontes de matérias-primas não renováveis, como também modos e meios de vida da diversidade de seres vivos. A pandemia causada pelo vírus SARS-CoV2, e todas as mazelas que se desdobram, são apenas mais uma expressão das consequências dos caminhos que essa dinâmica de acumulação vem trilhando, e provam a incapacidade desse sistema de se relacionar de forma distinta com a natureza, de gerar qualidade de vida e reais possibilidades de apropriação coletiva da riqueza socialmente produzida.

A forma como essa sociabilidade se conforma sob ditames mercantis, com centralidade na produção do valor e na mercadoria, gera modos de vida especificamente nos referimos à agricultura e à urbanização, como ambientes férteis para

\footnotetext{
${ }^{6}$ Exemplo recente refere-se à Nota Técnica emitida pela Fundação Oswaldo Cruz sobre o desastre de Brumadinho em janeiro de 2019, a partir do rompimento de uma barragem de responsabilidade da empresa Vale. A nota alerta para o aumento de surtos de doenças infectocontagiosas, como febre amarela, em decorrência das transformações produzidas no ecossistema. Parte da Nota salienta ainda que "as alterações ecológicas provocadas pelo desastre podem promover a transmissão de esquistossomose, principalmente se levado em consideração que grande parte do município de Brumadinho e municípios ao longo do rio Paraopeba não é coberto por sistemas de coleta e tratamento de esgotos" (FIOCRUZ, 2019, p. 9). Cerca de quatro meses após o alerta, a cidade de Brumadinho já registrava um surto de dengue.
} 
que infecções provenientes de animais contaminem humanos de forma crítica. Esse ambiente

fornece o meio ideal através do qual pragas cada vez mais devastadoras nascem, transformam-se, são induzidas a saltos zoonóticos e, em seguida, agressivamente vetorizadas através da população humana. [...] O coronavírus mais recente, em suas origens "selvagens" e sua súbita disseminação por um núcleo fortemente industrializado e urbanizado da economia global, representa as duas dimensões da nossa nova era de pragas político-econômicas. (COLETIVO CHUANG, 2020, sem paginação)

Fica claro, portanto, como as epidemias possuem caráter socialmente constitutivo como desastres ambientais. É nesse sentido que ponderamos que a pandemia da COVID19 não é a causa das mazelas atuais, tampouco personifica a crise em si, mas consiste em uma das expressões do desenvolvimento nessa forma social. Pode ser compreendida, nesse sentido, não como o que pode gerar o colapso do sistema, mas, sem trocadilhos, como parte da expressão de um sistema que colapsa contínua e profundamente desde os anos de 1970, quando passa a demonstrar abertamente a sua incapacidade de reproduzir valor, recorrendo permanentemente ao belicismo, à destruição e à financeirização como recurso de extração de valor (KURZ, 1997).

Não sendo diferente no Brasil, vivenciamos aqui um processo contraditório, confuso e exaustivo no trato cotidiano da pandemia gerada pelo SARS-CoV2. Tratando mais especificamente sobre seus determinantes, podemos citar elementos que contribuíram para a disseminação rápida do vírus e desenvolvimento da doença COVID-19 no país e que agravam seu enfrentamento. Conforme relacionamos no primeiro momento deste trabalho, ao se refletir sobre as particularidades de nossa formação social, é importante considerar:

(i) A existência de uma formação social esgarçada com profundos aspectos de desigualdade social de corte racial e patriarcal;

(ii) O crescimento de um movimento negacionista em relação à ciência, o qual difunde a ideia de ser o COVID-19 uma doença simples, uma "gripezinha" (mesmo que cientistas e fatos de todo o mundo, comprovem o contrário); 
(iii) A ação de grupos políticos conservadores que estigmatizam e relacionam as orientações das organizações internacionais de saúde e de pesquisadores como ideias "comunistas" sendo propagadas (isso se agrava a partir do confronto na atualidade às metanarrativas);

(iv) A defesa de uma perspectiva neoconservadora de valorização do hoje, do imediato e de recusa à razão e à ciência;

(v) A investida da política neoliberal a partir da defesa do Estado mínimo, do socorro ao setor privado e deterioração dos investimentos públicos no setor da saúde, superlotação e ausência de leitos públicos, com exposição de trabalhadores(as) sem a proteção devida. Simultaneamente a isso, ainda vivenciamos a flexibilização das relações trabalhistas de uma forma geral. Esses fatos contribuem para a produção de uma gama de trabalhadores “autônomos" e com vínculos empregatícios precarizados que necessitam se expor e aceitar condições precárias de trabalho, quando deveriam poder ter condições de permanecerem em suas casas.

Vale salientar que as evidências do colapso do capital não têm se expressado somente a partir dos constantes processos de desastres ambientais que a sociedade tem experimentado, ou por meio dos elementos complexificadores dos mesmos (como vimos acima), mas também através de respostas dadas a esses contextos, fomentando falsas polêmicas como: assegurar o isolamento social ou rompê-lo para "salvar" a economia", expondo vidas que podem se perder.

Ainda que seja necessário matizar as distintas épocas históricas e particularidades dos lugares, faz-se fundamental destacar aqui práticas difundidas desde a origem do capitalismo, como a responsabilização individual, a estigmatização racista e classista, além de decisões no âmbito da gestão majoritariamente voltadas a priorizar as condições

\footnotetext{
7 Essa falsa polêmica tem tensionado o cotidiano de manutenção do isolamento não apenas no Brasil, mas em outros países, como os EUA. Conforme debate pautado pela ABRASCO (Associação Brasileira de Saúde Coletiva), especialistas problematizaram em 23 de abril os aspectos centrais que transformam essa dualidade em uma abordagem superficial e perigosa quanto à questão. Ver https://www.abrasco.org.br/site/sem-categoria/painel-debate-falso-dilema-entre-salvar-a-economia-ou-asaude-durante-a-pandemia/47292/
} 
necessárias à retomada da acumulação capitalista. Essa forma de enfrentamento das epidemias marcou a Inglaterra na era industrial, quando

\begin{abstract}
os surtos foram contidos por meio de abate precoce seletivo e em menor escala, combinado com a aplicação de práticas médicas e científicas modernas - em essência semelhantes à forma como essas epidemias são combatidas atualmente. Esta é a primeira instância do que se tornaria um padrão claro, imitando o das próprias crises econômicas: colapsos cada vez mais intensos que parecem colocar todo o sistema em um precipício, mas que são superados por meio de uma combinação de sacrifício em massa que limpa o mercado / população e de intensificação dos avanços tecnológicos - nesse caso, as práticas médicas modernas somadas às novas vacinas, muitas vezes chegando tarde demais, mas mesmo assim ajudando a limpar as coisas após a devastação. (COLETIVO CHUANG, 2020, sem paginação)
\end{abstract}

São duras essas perspectivas, mas expressam a leitura pragmática e utilitária que estrutura essa sociabilidade desde sua constituição - e adquire contornos perversos na medida em que se aprofundam crises de acumulação. A despeito das promessas originárias das revoluções burguesas do século XVIII em torno de uma tríade que constrói aparente consenso em torno da positivação de valores como o universalismo da ciência, dos direitos humanos, e da meritocracia (WALLERSTEIN, 2011), a realidade que vivenciamos é brutalmente diferente.

Obviamente, da mesma forma em que não há a distribuição equitativa do que se produz socialmente a partir da enorme potencialidade produtiva gerada pelos avanços tecnológicos e a intensificação das condições de trabalho, também não há a padronização e o atendimento universal a todos e todas, sem distinção, no enfrentamento de pandemias e de consequências outras de desastres ambientais.

Os falsos dilemas, como a dicotomia "salvar a economia" versus "salvar vidas", obnubilam o que se entende por sujeitos econômicos em uma hierarquia superior àqueles cujas vidas podem se perder, pois não seriam centrais para a acumulação - especialmente em seu momento de generalização da financeirização e do capital especulativo, com a consequente drástica destruição de postos de trabalho. 
Enquanto escrevíamos este artigo, a mídia noticiava cotidianamente fluxos de abertura e de esgotamento das vagas em diversos hospitais do Rio de Janeiro para atendimento às pessoas com manifestação da COVID-19, sendo necessária a transferência de pacientes para outros municípios - todavia, as mortes pela incapacidade de atendimento à demanda foram significativas (SARTORI, 2020; CASTRO, 2020; NITAHARA, 2020). Tal realidade evidencia ainda mais que a perspectiva do sistema capitalista é que a

\begin{abstract}
inesgotável tentativa do capital de submeter absolutamente tudo aos imperativos que emanam "de sua natureza" deve ser prosseguida e forçosamente imposta, mesmo quando os resultados são destrutivos em escala mundial e em todos os sentidos. Mesmo quando o caminho seguido põe em perigo a sobrevivência não apenas da humanidade, mas ao mesmo tempo do sistema do capital como tal. [...] o resultado é que o capital não percebe nem sequer o desastre máximo implícito em seu modo de ultrapassar limites e derrubar obstáculos. E aqueles que continuam a repetir o slogan de que "não há alternativa" ignoram que com tal afirmação aceitam, queiram ou não, o suicídio da humanidade que está em correspondência com as determinações atuais. (MÉSZÁROS, 2014, p. 26-27)
\end{abstract}

Essa é a realidade que cerca a todos. Sabe-se que a mercantilização e a centralidade da dinâmica econômica sendo postas acima dos cuidados com a saúde afetam mortalmente a muitos.

\title{
Considerações finais
}

A reflexão realizada teve como objetivo, dentro de contexto de aprofundamento do colapso do capital, fundamentar a qualificação da pandemia gerada pelo vírus SARSCoV-2 como desastre ambiental. Para tanto, recorremos à compreensão da noção de desastre ambiental como processo social e historicamente construído.

Para essa qualificação crítica, problematizamos a lógica hegemônica do desenvolvimento nessa forma social e as consequências previsíveis, mas não menos nefastas em curso. É nesse sentido que articulamos esse debate à defesa de que os desastres ambientais consistem em processos socialmente produzidos, cujo discurso 
econômico e a dinâmica mercantil procuram hegemonizar como fatalidades pontuais e naturais.

Posteriormente - partindo do reconhecimento desse cenário como fruto de profundo resultado da forma predatória de desenvolvimento da acumulação capitalista -, procuramos substanciar que, sendo essa expansão do SARS-CoV-2 compreendida também como um desastre ambiental, isso nos traz indicações sobre os limites dessa forma social em sua expressão de colapso. Para tanto, foi necessário convergir leituras sanitaristas que articulam saúde pública, economia e ambiente de uma forma integrada.

Nesse sentido, sinalizamos brevemente determinações do processo de desastre ambiental com bases na forma como o mundo moderno se constitui. Essa compreensão contribuiu para uma posição teórica crítica a respeito desse conceito, para além de trazer à tona os distintos e desiguais impactos causados nas vidas das pessoas atingidas.

Essa é uma difícil tarefa, na medida em que questiona leituras naturalizadoras e fatalistas que tendem a tratar o desastre ambiental de forma unidimensional, como sendo fruto de fenômenos naturais inevitáveis. Ao trazer outra perspectiva de análise, pautada na compreensão sobre condicionalidades e processos, passa-se a identificar o papel das dinâmicas sociais produzidas pela acumulação capitalista, das (in)consequentes ações estatais a partir de tensões e interesses de agentes privados em uma sociedade fundada na noção de desenvolvimento como crescimento predatório e na exploração social e ambiental fundados nas desigualdades originárias de contradições entre as classes sociais.

A conformação da sociabilidade capitalista, desde sua gênese até os dias atuais, contribui decisivamente para a construção/intensificação dos processos de desastres ambientais, nos quais se integram as pandemias, como a que vivenciamos neste triste momento.

Identificamos que essa influência impulsionada pela busca desenfreada de valorização, se infiltra em diversos aspectos da vida cotidiana: na super exploração humana e dos recursos naturais; na superprodução somada à obsolescência programada, o que desemboca em amontoados de lixo e mesmo resíduos tóxicos; na mercadorização 
de todas as coisas e mesmo das relações sociais, atribuindo preço ao que não possui valor.

O avanço da técnica como elemento-chave da ideia de progresso e associado diretamente ao incremento da economia capitalista não se conecta em momento algum às dimensões universais de partilha equânime de seus benefícios, especialmente se nos referimos às populações periféricas, empobrecidas e não brancas. São centralizadas pela demanda internacional de corporações, contribuindo para a concentração de riqueza e aprofundamento das desigualdades sociais, globalizando "apenas" as mazelas ambientais, as quais atingem desigualmente as pessoas.

Muitos podem ser os discursos políticos que tentam demonstrar como conquistaram o aumento do crescimento econômico em seus países, no entanto, a tradução disso para a melhora na qualidade de vida da população em situação mais vulnerável é algo bem mais difícil. Nesse sentido, não é na chave desse sistema que construiremos os caminhos para a prevenção dos riscos e desastres. A existência desse sistema é que fomenta esses fenômenos a partir das suas características já pontuadas aqui, sobretudo a partir da intensificação da crise estrutural do capital, expressão maior do colapso já em curso.

É nítido, portanto, que as promessas de um mundo melhor por meio do progresso técnico e científico não se concretizam na realidade e apenas escancaram, especialmente na atualidade, a incapacidade do sistema capitalista de atender às demandas de reprodução da sociedade. Não obstante ser o sistema econômico que mais produziu riqueza, conhecimento e tecnologia em toda a história, hoje se mostra incapaz de promover os recursos necessários para o enfrentamento de um vírus.

\section{Referências}

BECK, Ulrich. Sociedade de risco: rumo a uma outra modernidade. Rio de Janeiro: Editora 34, 2010.

BONENTE, Bianca Imbiriba. Desenvolvimento em Marx e na teoria econômica: por uma crítica negativa do desenvolvimento capitalista. Niterói: Eduff, 2016. 
BRASIL. MINISTÉRIO DA SAÚDE. Sobre a doença. Brasília: Ministério da Saúde, 2020. Disponível em: https://coronavirus.saude.gov.br/sobre-a-doenca\#o-que-e-covid. Acesso em: 20 abr. 2020.

BRASIL. MINISTÉRIO DA INTEGRAÇAO NACIONAL. Instrução Normativa Nº $\mathbf{0 1}$, de 24 de agosto de 2012. Brasília: Ministério da Integração Nacional, 2012a. Disponível em: http://www.defesacivil.ma.gov.br/files/2014/10/Instrucao_normativa_de_01_de_agosto_d e_2012.pdf. Acesso em: 20 abr. 2020.

BRASIL. MINISTÉRIO DA INTEGRAÇAO NACIONAL. Ministério da Integração Nacional. Classificação e Codificação Brasileira de Desastres (Cobrade). Brasília: Ministério da Integração Nacional, Secretaria Nacional de Defesa Civil, 2012b.

CARMO, Roberto Luiz do; ANAZAWA, Tathiane Mayumi. Mortalidade por desastres no Brasil: o que mostram os dados. Ciênc. saúde coletiva, Rio de Janeiro, v.19, n. 9, set. 2014.

CASTRO, Nathália. Sem vaga no Rio, técnico de enfermagem morre com sintomas de Covid-19 em hospital no interior. Jornal G1, Rio de Janeiro, 24 abr. 2020. Disponível em: https://g1.globo.com/rj/rio-de-janeiro/noticia/2020/04/24/sem-vaga-no-rio-tecnico-deenfermagem-morre-com-sintomas-de-covid-19-em-hospital-no-interior.ghtml. Acesso em: 30 abr. 2020.

CHALHOUB, Sidney. Cidade febril: cortiços e epidemias na Corte imperial. São Paulo: Companhia das Letras, 1996.

COLETIVO CHUANG. Contágio Social - coronavírus, China, capitalismo tardio e o 'mundo natural'. Disponível em: http://afita.com.br/outras-fitas-contagio-social-coronavirus-chinacapitalismo-tardio-e-o-mundo-natural/. Acesso em: 30 abr. 2020.

DUTRA, Adriana Soares. Gestão de desastres e Serviço Social: o trabalho de assistentes sociais junto aos órgãos municipais de proteção e defesa civil. Rio de Janeiro: Lumen Juris, 2018.

ENGELS, Friedrich. Sobre a questão da moradia. São Paulo: Boitempo editorial, 2015.

FIOCRUZ - Fundação Oswaldo Cruz. Avaliação dos impactos sobre a saúde do desastre da mineração da Vale (Brumadinho, MG): nota técnica. Rio de Janeiro: Fiocruz, 01 fev. 2019. Disponível em: https://www.arca.fiocruz.br/bitstream/icict/32268/3/

Nota_Tecnica_Brumadinho_impacto_Saude_01022019.pdf. Acesso em: 30 abr. 2020.

GILBERT, C. Studying disaster: a review of the main conceptual tools. International Journal of Mass Emergencies and Disasters, v. 13, n. 3, p. 231-240, 1995. 
HARVEY, David. Os limites do capital. São Paulo: Boitempo, 2013.

HEWITT, Kenneth. Regions of risk: a geographical introduction to disasters. Harlow: Longman, 1997.

KURZ, Robert. Crise do valor de troca. Rio de Janeiro: Editora Consequência, 2017.

KURZ, Robert. Os últimos combates. Petrópolis: Editora Vozes, 1997.

MACHADO, Luiz Toledo. A teoria da dependência na América Latina. Estudos Avançados, v.13, n. 35, 1999.

MASCARO, Alysson Leandro. Estado e forma política. São Paulo: Boitempo Editorial, 2013.

MENEGAT, Marildo. A crítica do capitalismo em tempos de catástrofes: o giro dos ponteiros do relógio no pulso de um morto. Rio de Janeiro: Editora Consequência, 2019.

MÉSZÁROS, István. Marx, nosso contemporâneo, e seu conceito de globalização. In: ANTUNES, Ricardo (org.). Riqueza e miséria do trabalho no Brasil III. São Paulo: Boitempo, 2014.

MÉSZÁROS, István. A crise estrutural do capital. São Paulo: Boitempo, 2011.

NAYYAR, Deepak, A corrida pelo crescimento: Países em desenvolvimento na economia mundial. Tradução: Vera Ribeiro. Rio de Janeiro: Contraponto, 2014.

NITAHARA, Akemi. Vagas na rede municipal de saúde do Rio para covid-19 estão esgotadas. Agência Brasil, Rio de Janeiro, 22 abr. 2020. Saúde. Disponível em: https://agenciabrasil.ebc.com.br/saude/noticia/2020-04/vagas-na-rede-municipal-desaude-do-rio-para-covid-19-estao-esgotadas. Acesso em: 25abr. 2020.

O CAMINHO para nossa próxima pandemia. EcoDebate, 27 abr. 2020. ISSN 2446-9394. Disponível em: https://www.ecodebate.com.br/2020/04/27/o-caminho-para-nossaproxima-pandemia/. Acesso em: 06 abr. 2020.

OMS - ORGANIZAÇÃO MUNDIAL DA SAÚDE. Folha informativa. [S.I.]: OMS, 2020. Disponível em: https://www.paho.org/pt/covid19. Acesso em: 01 set. 2020.

ORGANIZAÇÃO MUNDIAL DA SAÚDE - OMS. Perguntas e respostas sobre coronavírus (COVID-19). 2020a. Disponível em: https://www.who.int/news-room/q-a-detail/q-acoronaviruses. Acesso em 20 abr. de 2020. 
ORGANIZAÇÃO MUNDIAL DA SAÚDE - OMS. Coronavirus disease 2019 (COVID-19). Situation Report - 92. 2020b. Disponível em: https://www.who.int/docs/defaultsource/coronaviruse/situation-reports/20200421-sitrep-92-covid19.pdf?sfvrsn=38e6bo6d_6. Acesso em: 20 abr. de 2020.

SARTORI, Caio. Rede estadual do Rio de Janeiro não tem mais leitos de UTI para COVID-19 na capital. O Estado de S. Paulo, São Paulo, 28 abr. 2020. Disponível em: https://saude.estadao.com.br/noticias/geral,rede-estadual-do-rio-nao-tem-mais-leitos-deuti-para-covid-19-na-capital,70003281397. Acesso em: 28 abr. 2020.

SHIVA, Vandana. Um vírus, a humanidade e a terra. IHU On-line, São Leopoldo, 15 abr. 2020. Disponível em: http://www.ihu.unisinos.br/78-noticias/598043-um-virus-ahumanidade-e-a-terra-artigo-de-vandana-shiva. Acesso em: 20 abr. 2020.

STARK, Evan. The Epidemic as a Social Event. International Journal of Health Services, v. 7, n. 4, 1977, p. 681-705. Disponível em:

https://journals.sagepub.com/doi/pdf/10.2190/RKRQ-WV6E-DV53-VATT. Acesso em julho de 2020.

UFSC - UNIVERSIDADE FEDERAL DE SANTA CATARINA. Capacitação básica em defesa civil. 5. ed. Florianópolis: CEPED UFSC, 2014.

WALLERSTEIN, Immanuel. O fim do mundo como o concebemos: ciência social para o século XXI. Rio de Janeiro: Editora Revan, 2011.

WALLERSTEIN, Immanuel. Capitalismo histórico e civilização capitalista. Rio de Janeiro: Contraponto, 2001.

Recebido em: $28 / 04 / 2020$

Aprovado em: 18/09/2020

Universidade do Estado de Santa Catarina - UDESC Centro de Ciências Humanas e da Educação - FAED

PerCursos

Volume 21 - Número 46 - Ano 2020 revistapercursos@gmail.com 